\title{
OLHANDO O PASSADO, CONSTRUINDO O FUTURO: A SEGURANÇA ALIMENTAR NO RESGUARDO INDÍGENA GUACHICONO, COLÔMBIA
}

\author{
Maria Jesus Chicangana Hormiga ${ }^{1}$ \\ Doris Sayago $^{2}$
}

\section{Introdução}

A segurança alimentar ${ }^{3}$ é um tema polêmico, tanto no campo político quanto no acadêmico considerando-se que mesmo havendo alimentos suficientes para a população do mundo inteiro, até o ano 2014, 805 milhões de pessoas passavam fome (Organização das Nações Unidas para a Alimentação e a Agricultura - FAO, 2014). No campo acadêmico não há consenso enquanto ao conceito, possuindo um viés mais político. Alguns autores de destaque no estudo da segurança alimentar (Pérez-Escamilla, 2005; Alvarez et al, 2006; Kepple \& Segall-Corrêa, 2011; Pérez-Escamilla, 2012) formam parte, ao mesmo tempo da FAO, o que dificulta seu posicionamento crítico. Uma abordagem alternativa surge com uma análise crítica da segurança alimentar para o caso latino-americano. Os críticos (Katz, 2009; Oseguera \& Esparza, 2009; Pat, 2010; Rosique, 2010; Heusi, 2011; Lemos, 2011; Fernandes, 2014) argumentam que a segurança alimentar não pode limitar-se às cifras, porque mesmo sendo um problema global, as políticas públicas não podem estar padronizadas. As conclusões desses estudos indicam que as políticas públicas de segurança alimentar para as populações tradicionais não são sustentáveis, pois desconhecem as suas particularidades.

Atualmente inexistem pesquisas acadêmicas específicas sobre segurança alimentar no Povo Yanacona, encontram-se sim, análises antropológicas do processo de construção do povo e dos conflitos socioambientais, como também abordagens históricas da formação da comunidade. Esses estudos e documentos indicam que a partir de 1990 os indígenas Yanaconas residentes em seis departamentos da Colômbia sofreram mudanças drásticas nos seus sistemas alimentares. As aproximações mostram

\footnotetext{
${ }^{1}$ Universidade de Brasília, Brasil.

${ }^{2}$ Universidade de Brasília, Brasil.

${ }^{3}$ Para efeitos deste estudo, entende-se como segurança alimentar "a realização do direito de todos ao acesso regular e permanente a alimentos de qualidade, em quantidade suficiente, sem comprometer o acesso a outras necessidades essenciais, tendo como base práticas alimentares promotoras de saúde, que respeitem a diversidade cultural e que sejam social, econômica e ambientalmente sustentáveis" (BRASIL, 2006: 1).
} 
uma deterioração da sua segurança alimentar, determinada por fenômenos que se apresentaram conjuntamente a partir da década de 1980 (López-Garcés, 1999; Cabildo Mayor Yanacona, 2001; Camargo, 2010).

Os fenômenos, aqui colocados como determinantes, são o conflito armado entre guerrilha, paramilitares e força pública, os cultivos ilícitos de papoula e a fumigação aérea com glifosato feita pelo governo Nacional ${ }^{4}$ para erradicar os cultivos ilícitos. As fumigações incidiram negativamente no ecossistema, tornando as terras pouco férteis (além de já serem escassas em extensão para os indígenas). A qualidade da água também decaiu. Apareceram doenças que antes não existiam. Perderam-se as práticas agrícolas tradicionais que permitiam às famílias satisfazerem as suas necessidades de alimentação. Parte da população se deslocou para as cidades por causa do confronto armado. Como apontam vários autores, as políticas do governo nacional não responderam às necessidades da população, por serem focalizadas e não enfrentarem os problemas estruturais (López-Garcés, 1999; Bernal \& Paredes, 2008; Camargo, 2010).

$\mathrm{O}$ artigo tem como objetivo analisar o estado atual de segurança alimentar do Resguardo ${ }^{5}$ indígena Guachicono. A análise qualitativa da segurança alimentar desse povo se faz a partir da compreensão dos sistemas alimentares e a identificação dos fatores determinantes das mudanças nesses sistemas.

\section{Procedimentos metodológicos}

A pesquisa é de caráter qualitativo. Os dados foram levantados mediante trabalho de campo com duração de três meses. A área de estudo é o Resguardo indígena Guachicono, que junto com mais 30 comunidades compõem o povo Yanacona. O Resguardo está localizado no sudoeste da Colômbia, no Departamento do Cauca. Está a uma distância de 39 quilômetros do povoado central do município da Vega e a 104 quilômetros de Popayán (capital do Departamento) (Ver Figuras1 e 2). Ocupa parte das montanhas conhecidas como maciço colombiano. As suas condições ambientais como

\footnotetext{
${ }^{4}$ Colômbia é uma república unitária descentralizada e não federativa como é o Brasil, portanto usa-se a expressão governo Nacional.

${ }^{5}$ Resguardo na Colômbia "é uma instituição legal e sociopolítica de caráter especial, conformada por uma comunidade ou parcialidade indígena, com título de propriedade comunitária, tem seu território e se guia para o manejo deste e de sua vida interna por uma organização ajustada ao fuero (estatutos jurídicos aplicados para regulamentar a vida local) indígena ou a suas pautas e tradições culturais" (Tradução livre do Decreto No. 2001 de 1988). In: https://www.cancilleria.gov.co/sites/default/files/Normograma/docs/decreto_2001_1988.htm)
} 
clima, hidrografia e orografia são importantes para o equilíbrio ambiental do país (Camargo, 2010). Ocupa um território de 136,5 $\mathrm{km}^{2}$ e está localizado entre os pisos térmicos frios e páramo ${ }^{6}$, a uma altura de 2.760 metros sobre o nível do mar, com una temperatura média anual de $9^{\circ} \mathrm{C}$. (http://ieayanaconas.blogspot.com.br/p/ubicaciongeografica.html, acesso em junho de 2015). Nesse Resguardo habitam aproximadamente 4.682 pessoas (Censo interno, 2012). O Resguardo está dividido em 14 veredas $^{7}$; estas, por sua vez, conformam quatro blocos definidos de acordo com as características de clima e relevo.
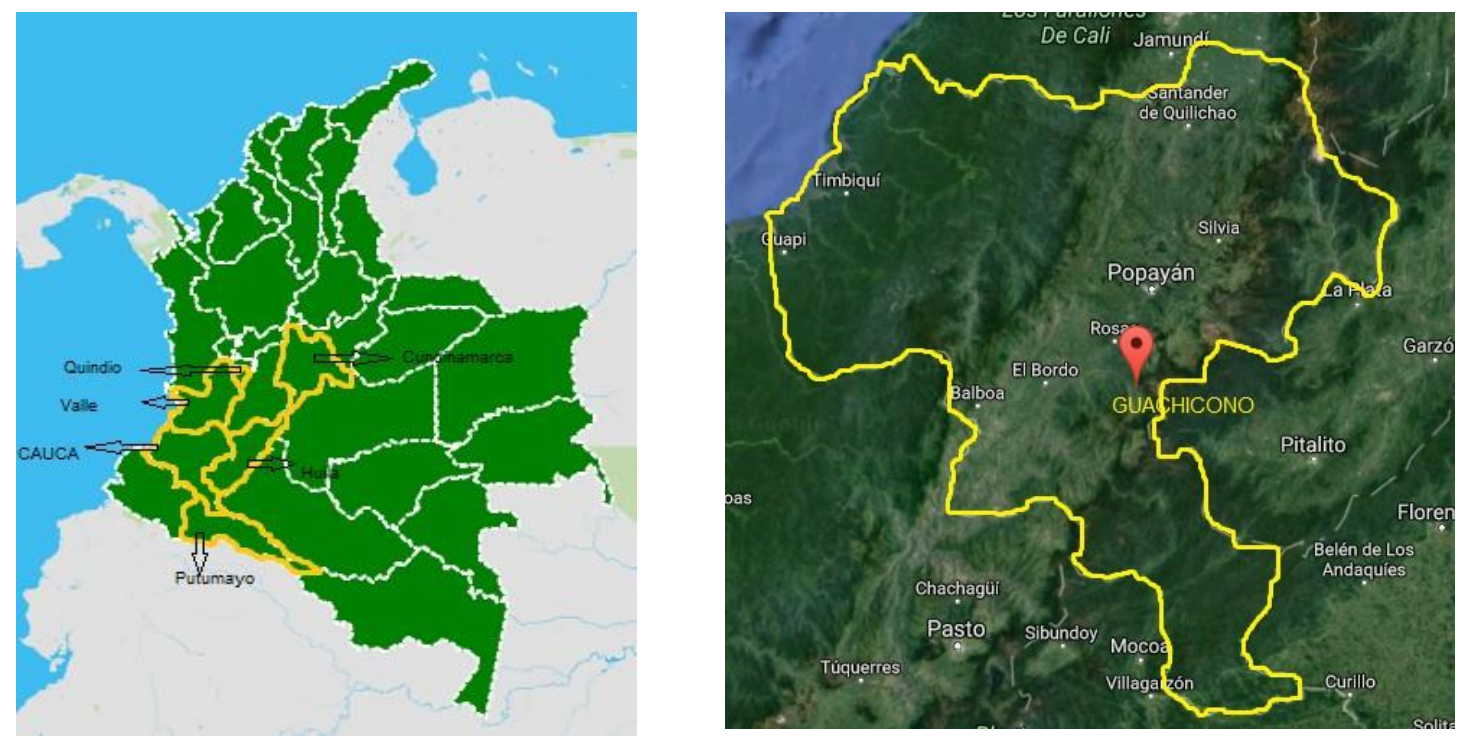

Figura 1 (à direita): Localização do Resguardo Guachicono no Departamento do Cauca.

Figura 2 (à esquerda): Localização geográfica do Povo Yanacona na Colômbia.

Fonte: adaptado do Google Maps, 2016.

O critério para a seleção da amostra selecionada foi escolher uma vereda de cada um dos blocos que compõem o Resguardo. Buscou-se obter uma representatividade de todo o Resguardo, por esse motivo foram entrevistadas pessoas do Resguardo que moram transitoriamente na cidade de Popayán. Em campo foram aplicadas quatro técnicas, a saber: entrevistas semiestruturadas, mapas mentais, grupos focais e observação participante (Ver tabela 1).

\footnotetext{
${ }^{6}$ Parte mais elevada da Cordilheira dos Andes, lugar extremamente frio e de difícil acesso.

${ }^{7}$ Termo usado na Colômbia para definir uma seção administrativa de um município (DICCIONARIO DE LA LENGUA ESPAÑOLA, 2014).
} 


\begin{tabular}{|c|c|c|c|c|}
\hline VEREDA/ZONA & $\begin{array}{c}\text { No } \\
\text { HABITANTES }\end{array}$ & $\begin{array}{c}\text { No } \\
\text { ENTREVISTAS }\end{array}$ & $\begin{array}{c}\text { No } \\
\text { MAPAS } \\
\text { MENTAIS }\end{array}$ & $\begin{array}{c}\text { No } \\
\text { GRUPOS } \\
\text { FOCAIS }\end{array}$ \\
Alto de la Playa & 159 & 9 & 4 & \\
Monteredondo & 168 & 5 & 2 & \\
Alto de las Palmas & 496 & 9 & 2 & 1 \\
Guachicono Centro & 744 & 10 & 0 & \\
Pepayán & 705 & 5 & 0 & $\mathbf{1}$ \\
TOTAL & $\mathbf{2 2 7 2}$ & $\mathbf{3 8}$ & $\mathbf{8}$ & \\
\hline
\end{tabular}

Tabela 1 - Amostra e técnicas aplicadas.

Fonte: Pesquisa de Campo, 2015.

As entrevistas semiestruturadas permitiram levantar dados históricos e atuais dos sistemas alimentares. As entrevistas foram feitas com as lideranças e também com os mais idosos (tanto homens como mulheres). Os mapas mentais permitiram reconstruir realidades territoriais, foram elaborados pela população masculina em idade adulta (entre 18 e 60 anos), porque a atividade de exploração do território era na sua maioria realizada por homens adultos na companhia dos filhos jovens do sexo masculino. $\mathrm{O}$ grupo focal foi realizado na etapa final do campo para validar a informação e, por sua vez, realizar a restituição preliminar dos resultados da pesquisa para a comunidade.

Durante a pesquisa de campo conviveu-se com a comunidade, conseguindo a participação em eventos de discussão política do Povo Yanacona. O instrumento que auxiliou a observação foi o caderno de campo para registrar as informações observadas nos diferentes eventos diários.

Os dados foram analisados e apresentados por semelhança, em uma linha do tempo que apresenta os sistemas alimentares e os fatores determinantes de cada um deles. A comunidade estudada foi informada da pesquisa e seus objetivos e quando consultada assinou o consentimento livre e esclarecido para o início do trabalho. $\mathrm{Na}$ restituição preliminar de resultados feita ao finalizar o campo, a comunidade solicitou que o documento final de conclusão da dissertação de mestrado defendida e aprovada pelo Centro de Desenvolvimento Sustentável da Universidade de Brasília fosse entregue em língua espanhola para conhecimento e divulgação na comunidade. A tradução foi concluída, contudo a devolução dos dados está sendo acertada com as novas lideranças, definindo-se a melhor data para a comunidade. 


\section{A segurança alimentar}

A segurança alimentar é um conceito polêmico e ainda em construção. $O$ conceito tem estado ligado à fome e aos direitos fundamentais do ser humano. A fome como problema social foi abordado no século XVIII por Thomas Malthus, argumentava que o crescimento demográfico geraria fome e miséria por ultrapassar a capacidade produtiva da terra. A chamada revolução verde se apoia na teoria de Malthus e,entre 1930 e 1980 procura substituir a produção extensiva tradicional de alimentos pela produção intensiva. O resultado é o aumento global de $5 \%$ da produção per capitai na década de 1980, mas a produção per capita de 75 países em desenvolvimento era menor ao final da década de oitenta do que ao início (Nascimento, 2010).

A segurança alimentar como conceito surge no século $\mathrm{XX}$, na primeira guerra mundial associado à segurança nacional. Sumiu por uns anos e foi retomado depois da segunda guerra mundial quando a Europa não estava dando conta de produzir nem seus próprios alimentos. A discussão de segurança alimentar estava ligada à segurança internacional e à manutenção da paz. Na década de 1970 com a I Conferência Nacional de Alimentação organizada pela FAO e a escassez de alimentos, a segurança alimentar ganhou importância no contexto mundial. O enfoque de segurança alimentar nessa época era de disponibilidade de alimentos, considerando que o problema da fome estava associado à escassez de alimentos (Alencar, 2001; Nascimento, 2010; Lemos, 2011).

As medidas dos governos dos países da América Latina para garantir a disponibilidade de alimentos foram o aumento das importações de suprimentos alimentícios e a redução dos seus preços. O resultado foi que mesmo aumentando as importações e reduzindo os preços dos alimentos, a fome não tinha acabado. A conclusão foi que o aumento da disponibilidade de alimentos não significava que todos pudessem ter acesso a eles (Kepple \& Segall, 2011).

Na década de 1980 a fome estava associada com pobreza. O enfoque foi o de segurança alimentar no nível familiar, centrada no acesso aos alimentos e na luta contra a pobreza. As medidas para acabar com a fome e a pobreza continuaram focadas no aumento das importações de alimentos, em políticas públicas de renda mínima da população mais carente e na aposta na redução dos preços dos alimentos. O resultado foi um quadro de fome nos níveis mundial, nacional e familiar (Monteiro, 2004; Lemos, 2011; FAO, 2014). Isso porque as importações começaram a afetar a oferta local que 
não estava preparada para competir com os preços dos alimentos importados de baixo custo.

O conceito de segurança alimentar muda a partir de 1990. A FAO organizou a cúpula mundial sobre a alimentação em 1996 com participação de mais de 180 países, representantes da comunidade europeia e organizações não governamentais. Uma das metas estabelecidas na cúpula foi reduzir, até o ano 2015, à metade o número de pessoas com fome ou desnutridas no mundo (Garcia, 2008). A preocupação de organizações internacionais como a FAO, do ponto de vista político, passou a ser garantir o abastecimento de alimentos para uma população mundial em crescimento e, ao mesmo tempo, conservar os ecossistemas, para que continuassem fornecendo recursos às gerações futuras (FAO, 2014), já que se estima que em 2050 a população mundial seja de 9,3 mil milhões de pessoas (Álvares \& Estrada, 2008).

A cúpula mundial sobre a alimentação que a partir de 1996 se realiza anualmente, contribuiu com a criação de um conceito mais integral de segurança alimentar. Aspectos individuais e coletivos, como a saúde, a nutrição, ganham relevância, mas na prática a abordagem se restringe à disponibilidade e ao acesso aos alimentos (Lemos, 2011). O conceito de segurança alimentar está ligado ao direito à alimentação e foi definido depois da cúpula como:

O direito à alimentação adequada realiza-se quando cada homem, mulher e criança, sozinho ou em companhia de outros, tem acesso físico e econômico, ininterruptamente, à alimentação adequada ou aos meios para sua obtenção. $O$ direito à alimentação adequada não deverá, portanto, ser interpretado em um sentido estrito ou restritivo, que o equaciona em termos de um pacote mínimo de calorias, proteínas e outros nutrientes específicos. O direito à alimentação adequada terá de ser resolvido de maneira progressiva. No entanto, os estados têm a obrigação precípua de implementar as ações necessárias para mitigar e aliviar a fome, mesmo em épocas de desastres, naturais ou não (Albuquerque, 2009: 896-897).

Os governos de diferentes países debatem o conceito definido na cúpula sobre a alimentação em 1996, e alguns como o Brasil o incorporam às suas políticas de segurança alimentar. $\mathrm{O}$ conceito adotado nesta pesquisa para analisar o estado de segurança alimentar é o seguinte: 
A realização do direito de todos ao acesso regular e permanente a alimentos de qualidade, em quantidade suficiente, sem comprometer o acesso a outras necessidades essenciais, tendo como base práticas alimentares promotoras de saúde, que respeitem a diversidade cultural e que sejam social, econômica e ambientalmente sustentáveis (BRASIL, 2006: 1).

No campo acadêmico do continente americano pesquisas têm procurado criar ferramentas para medir a segurança alimentar em grande escala, baseados no conceito definido pela FAO na cúpula mundial sobre a alimentação (Pérez-Escamilla, 2005; Alvarez et al, 2006; Kepple \& Segall-Corrêa, 2011; Pérez-Escamilla, 2012). Esses estudos justificam o seu enfoque pela inexistência de ferramentas padrão que permitam medir a segurança alimentar nos países americanos. O que tem sido desenvolvido é uma escala de percepção de segurança alimentar que está sendo validada e adaptada em diferentes países latino-americanos baseados na ferramenta US Household foof security survey measure desenvolvida nos Estados Unidos. Os autores acima citados conformam por sua vez o Comitê Científico da Escala Latino-americana e do Caribe de Segurança Alimentar da FAO (FAO, 2012), situação que talvez dificulte uma análise crítica da segurança alimentar tendo em consideração as características socioculturais especificas de cada país.

No campo acadêmico do México, Brasil e Colômbia, surgem estudos que têm uma posição crítica sobre como está sendo trabalhado o conceito de segurança alimentar (Gugelmin \& Santos, 2001; Katz, 2009; Oseguerra \& Esparza, 2009; Pat, 2010; Rosique, 2010; Heusi, 2011; Lemos, 2011; Fernandes, 2014). Esses estudos indicam que as políticas públicas de segurança alimentar dos diferentes países da América Latina desconhecem as particularidades das populações e as políticas públicas mostram-se pouco ou nada sustentáveis e geram mudanças drásticas nos sistemas alimentares, sem resgatar a importância do trabalho que as populações tradicionais estudadas nesses países vêm desenvolvendo na procura da autonomia e da soberania alimentar. Os estudos permitem compreender que a alimentação não é apenas uma prática que responde a uma necessidade biológica - é sobretudo uma prática simbólica relacionada com diversos contextos e com a história, e portanto precisa uma abordagem não só quantitativa. 
Entendendo esses contrapontos, o presente estudo aborda a segurança alimentar a partir de uma análise histórica dos sistemas alimentares. A segurança alimentar não pode ser abordada como uma cifra só, os processos que levaram a esse estado precisam ser analisados, permitindo compreender que a busca da segurança alimentar não é somente um ato biológico.

Nesse sentido, Maciel (2001), tomando como base os trabalhos de De Garine (1987), aponta que a escolha dos alimentos que viraram comida está relacionada ao meio no qual se encontra esse alimento e aos recursos técnicos que o homem possui, mas que esses fatores são deixados de fora por dimensões sociais e culturais do grupo ao qual esses indivíduos pertencem. A escolha dos alimentos está relacionada com uma classificação hierárquica estabelecida culturalmente. A cultura indica o que é e o que não é comida, mas também determina o que deve ser ingerido e quando. A cultura estabelece interdições, proibições, distinções, configurando assim o que é bom e o que não, estabelecendo tabus. Nesse sentido, os humanos se alimentam de acordo às sociedades às quais pertencem.

A sociedade ou grupo, além de definir o que é comida por meio de valores sociais e culturais, determina outros aspectos da alimentação: como se come, quando e com quem. A forma de comer os alimentos inclui as formas de preparo, as técnicas utilizadas e as formas de conservação. O número de refeições e composição delas é estabelecido, como também a comida para datas especiais. $\mathrm{O}$ aspecto de com quem se come gera divisões por sexo, idade, gênero, que transformam o ato alimentar num acontecimento social. É a relação desses aspectos que constituem os sistemas alimentares, conhecidos também como cozinhas. Os sistemas alimentares ou cozinhas representam uma complexificação do ato alimentar que vai além do biológico. Compreendem práticas alimentares relacionadas com o imaginário social, as representações sociais e com as práticas culturais que transformam o alimento em comida. As sociedades, grupos, povos ou comunidades não estão fechados ao entorno, por isso os sistemas alimentares construídos socialmente são permeados pelo contexto (Maciel, 2001). 


\section{Os Yanaconas e seu contexto}

$\mathrm{Na}$ Colômbia vivem 87 povos indígenas. A população indígena total aproximada é de 1.392.623 indivíduos, representando 3,43\% da população nacional. A maior parte da população indígena reside em zonas rurais do país. Aproximadamente 933.800 deles moram em 710 resguardos indígenas legalmente reconhecidos (Departamento Administrativo Nacional De Estadística - DANE, 2007).

Os Yanaconas, sociopoliticamente, formam um povo que habita em seis departamentos da Colômbia, a saber: Cauca, Putumayo, Huila, Valle, Cundinamarca e Quindio. Ocupam parte do ecossistema estratégico conhecido como maciço colombiano, onde nascem os principais rios do país (Patía, Caquetá, Cauca e Magdalena) (Camargo, 2010). O maciço colombiano (Departamento do Cauca) é considerado o território ancestral do Povo Yanacona. Os outros Departamentos são considerados territórios descontínuos ${ }^{8}$ nos quais os Yanaconas habitam como consequência do deslocamento dos Resguardos para as terras privadas ou zonas urbanas. As causas do deslocamento são principalmente a escassez de terra e o conflito armado entre forças ilegais e do Estado (Cabildo Mayor Yanacona, 2015).

O nome Yanacona surge do processo de reindigenização que começou nos anos de 1990. Esse processo levou a população dos Resguardos do maciço Colombiano a se identificar com esse nome, procurando nos seus passados vínculos com a sociedade Inca $^{10}$. As características principais que consolidam os Yanaconas como povo são a existência de um território comum, instituições de governo semelhantes e padrões culturais similares entre si, mas distintos dos de outros grupos étnicos. Uma característica importante é que os Yanacona apresentam baixos níveis de estratificação social (López-Garcés, 1999).

\footnotetext{
${ }^{8}$ Território descontinuo na concepção Yanacona é um território longe das raízes ancestrais ou dos Resguardos, mas que mantêm um vínculo pela conservação das tradições que perpassam os limites do físico.

${ }^{9}$ Conceito tomado de López-Garcés (1999) e entendido como um processo de reconhecimento, de busca de identidade e que usa a historia para legitimar a ação e coesão grupal e para fortalecer a autoridade própria.

${ }^{10}$ Foi um estado sul-americano que surgiu entre os séculos XV e XVI.
} 
O processo de reindigenização se traduz hoje no plano de vida do povo Yanacona, denominado "reconstruyendo la casa yanacona". O plano representa não somente a ideia do espaço físico que garante a sua subsistência, mas também o espaço político, com o fortalecimento dos Cabildos indígenas ${ }^{11}$. O espanhol é a língua oficial, mas usam-se algumas palavras derivadas do quéchua (língua do império inca). A religião é uma mistura de tradição mística com o cristianismo católico e evangélico (López-Garcés, 1999).

A estrutura política organizativa do Povo Yanacona é circular. O Cabildo mayor é a organização indígena representativa do Povo Yanacona, registrado perante o Ministério do Interior e Justiça - Direção de Etnias. 31 comunidades indígenas autônomas formam parte do Cabildo mayor que conta com um conselho diretivo. Cada uma das 31 comunidades tem um Cabildo como autoridade autônoma tradicional. O atual Cabildo mayor é produto do processo politico organizativo indígena que começou na década de 1960 procurando reivindicar os direitos sobre o território. Foi criado como organização indígena em 1992 com cinco resguardos (Cabildo Mayor Yanacona, 2001).

A década de 1990 foi determinante para o Cabildo mayor na consolidação da organização e no reconhecimento por parte da sociedade como povo Yanacona. A presença do cultivo ilícito de papoula no território Yanacona, ameaçou a organização indígena porque os Yanaconas mudaram radicalmente seus costumes. Por outra parte,o reconhecimento da autonomia dos povos indígenas na constituição política de 1991 impulsou a organização porque disponibilizou ferramentas legais para reivindicar direitos sobre a terra e a autonomia. A partir do ano 2000 o povo Yanacona fortalece a organização e o diálogo interinstitucional ${ }^{12}$.

Até o ano 2001 são reconhecidas como parte do povo Yanacona mais 10 comunidades indígenas residentes em zonas urbanas e terras rurais privadas (Cabildo Mayor Yanacona, 2001). O Povo Yanacona atualmente está conformado por 31 comunidades: os 5 Resguardos que o constituíram, 22 Cabildos assentados em terras rurais privadas e 4 Cabildos residentes em zonas urbanas.

\footnotetext{
${ }^{11}$ O Cabildo Indígena é uma "entidade pública especial, cujos integrantes são indígenas. O Cabildo representa legalmente o seu grupo e exerce funções que a lei atribui segundo os seus usos e costumes", segundo o Decreto No. 2001 de 1988.

In: https://www.cancilleria.gov.co/sites/default/files/Normograma/docs/decreto_2001_1988.htm.

${ }^{12} \mathrm{http}: / / \mathrm{www}$. cabildoyanaconasantiagodecali.com/. Acesso em março de 2016.
} 
As comunidades que habitam os territórios reconhecidos legalmente como Resguardos são constitucionalmente entendidas como entidades territoriais autônomas ao igual que os Municípios e Departamentos e chamadas de Resguardos, como é o caso da área de estudo. Nesse sentido os Resguardos são reconhecidos como de caráter coletivo e inalienável, têm o direito de se autogovernarem, administrarem seus próprios recursos e a participarem do orçamento da Nação (Procuraduría General de la Nación, 1991).

O Estado repassa desde 1994 os recursos per capita para os Resguardos indígenas, por intermédio das suas próprias organizações e autoridades. A transferência direta dos recursos aos Resguardos possibilita o investimento nos seus projetos de desenvolvimento socioeconômico, cultural e político conforme as suas necessidades. Os povos indígenas participam do regime subsidiado de atendimento em saúde por meio das Empresas Prestadoras de Serviços de Saúde (EPS) dedicadas exclusivamente ao atendimento dos povos indígenas. As EPS indígenas possuem autonomia administrativa, algumas são administradas pelas autoridades e organizações indígenas (L López-Garcés, 2004). No Cauca, mediante a resolução 083 de 15 de dezembro de 1997 é reconhecida legalmente a Asociación Indígena do Cauca (AIC EPS-I). A AIC EPS-I até o ano 2010 contava com 96 cabildos indígenas sócios, prestava serviços em seis departamentos da Colômbia (Cauca, Valle, Huila, Putumayo, Antioquia e Guajira) e tinha 267.146 afiliados (http://190.254.19.13:1080/saludAic/. Acesso fevereiro de 2016).

Os Resguardos têm jurisdição especial indígena que na prática se traduz na permissão que os povos indígenas têm de exercer a autonomia para aplicar as sanções aos seus integrantes ou pessoas não indígenas que estejam dentro de seus territórios (López-Garcés, 2004). No departamento do Cauca, por exemplo, permitiu o fortalecimento da guardia indígena ${ }^{13}$ como forma pacífica de exercer autoridade e levou ao fortalecimento da justiça como um processo de harmonização e não de castigo. Entre as funções da guardia está o controle da segurança nos Resguardos, mobilizações, marchas, congressos, assembleias (Ver figuras 3 e 4). É mecanismo de alerta nos casos de riscos de bombardeio, massacre ou outros atos do conflito armado (http://www.criccolombia.org/portal/guardia-indigena/. Acesso fevereiro de 2016).

\footnotetext{
${ }^{13}$ A guardia Indígena não é uma força policial, é um meio de resistência, unidade e autonomia para a defesa do território. A guardiaestá composta por crianças, jovens, adultos, mulheres e homens voluntários. O elemento distintivo é a chonta ou bastón de mando, como mostrado na figura 4.
} 


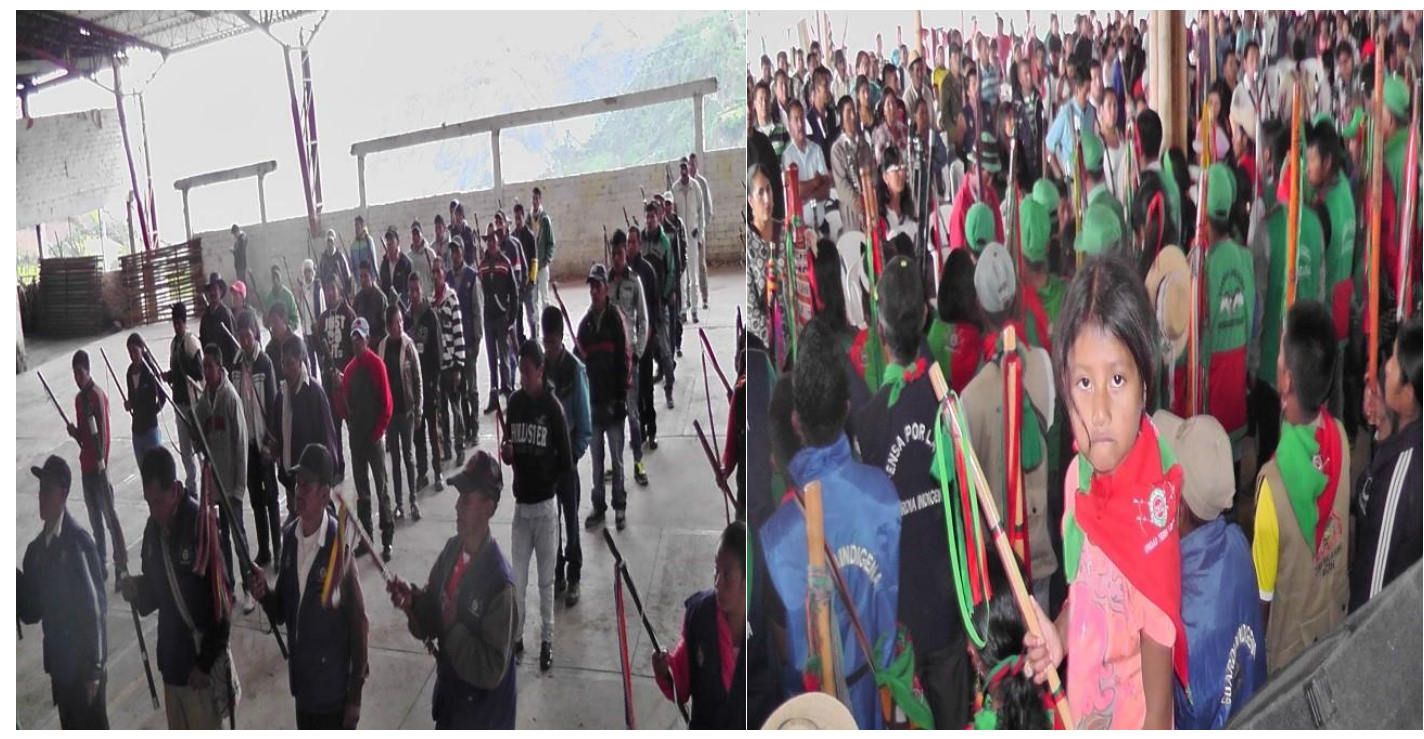

Figura 3 (à direita): A Guardia indígena não tem distinção de idade ou gênero. Observa-se a criança com o bastão, símbolo de autoridade, sendo preparada como futura liderança.

Figura 4 (à esquerda): Guardia indígena em encontro de povos indígenas convocado pelo Conselho Regional Indígena do Cauca em outubro de 2015.

Fonte: Trabalho de Campo, outubro de 2015.

\section{Resultados: Os sistemas alimentares}

A partir da análise dos dados da pesquisa no Resguardo indígena Guachicono foi possível identificar três sistemas alimentares que existiram entre 1980 e 2015. Cada um dos sistemas alimentares foi nomeado depois da análise de dados na procura de estabelecer relação com suas as características. O sistema alimentar de "autoconsumo" vigorou entre 1980 e 1989, aproximadamente. O sistema alimentar "bonanza de papoula" vigorou entre 1990 e 1999. O sistema alimentar "voltando às origens" foi adotado a partir de 2000. Nos parágrafos subsequentes será apresentado cada um desses sistemas. Será analisado cada sistema alimentar e, na sequência apresentam-se os fatores determinantes. 


\section{Sistema alimentar de autoconsumo (1980-1989)}

O sistema alimentar de autoconsumo apresenta características que revelam a história com os acontecimentos marcantes da década de 1980. A agricultura era a principal atividade produtiva no território Yanacona, seguida da pecuária. O cultivo de milho, trigo, cevada, tubérculos (batata) e legumes (cenoura, couve) foram o eixo da economia e da cozinha Yanacona. Dessa forma, a economia local apresentava uma relativa estabilidade, caracterizada por uma segurança alimentar, auto abastecimento, com uma equilibrada dependência externa de alimentos (Cabildo Mayor Yanacona, 2001).

A produção, a distribuição e o consumo incluíam valores culturais e sociais próprios, mas deixavam ver também a mistura com os costumes de camponeses próximos do Resguardo e algumas influências externas. O café, banana da terra, rapadura e frutas eram comprados ou trocados com esses camponeses que moravam em terras vizinhas privadas.

A exploração do meio ambiente para a produção de alimentos era feita pelos homens. Deviam ser respeitadas as fontes da água, as montanhas mais altas por onde desciam os riachos e mananciais. A prática agrícola de corte e queima era feita tomando o cuidado de não gerar incêndios fora de controle e a fronteira agrícola ia até os 3000 metros sobre o nível do mar. A produção de alimentos estava mediada pela espiritualidade inserida na cosmovisão indígena, a agricultura estava estreitamente relacionada com os fenômenos naturais como chuva, sol, ciclo da lua, fenômenos que determinavam as decisões agrícolas em tempo e espaço para plantio, manutenção e colheita. A agricultura estava libre do uso de produtos químicos.

As famílias produziam quase toda a alimentação. Os alimentos que não conseguiam cultivar pelas condições de clima eram trocados com parentes, compadres ou amigos. Mesmo havendo uma desigualdade na posse da terra e escassez geral da mesma, as famílias cultivavam de tudo, o que mudava era a quantidade cultivada. $\mathrm{O}$ milho, trigo, cevada, couve, batata, ulluco (nome cientifico ullucus tuberosus), cebolinha, haba (nome cientifico vicia faba) eram os alimentos que se produziam na chagra. A chagra era a horta indígena na qual se combinavam alimentos, plantas medicinais ou de controle biológico e plantas ornamentais. A produção incluía galinhas, porquinhos da índia, coelhos e em algumas outras localidades, também ovelhas. As 
famílias com maior quantidade de terra tinham gado de leite. Outras que não tinham terra suficiente tinham gado ou trabalhavam "de a medias". É uma forma social de trabalho na qual uma família põe o gado ou as sementes e outra família põe a terra, o produto é dividido por partes iguais ou como foi combinado no início da lavoura.

As tarefas eram separadas por gênero e idade. As mulheres tomavam conta dos afazeres da casa e de trabalhar a terra. As práticas sociais para produzir, distribuir, e consumir alimentos estavam baseadas na reciprocidade. A minga e a "troca de mão" eram formas de trabalho coletivo, que favoreciam a interação comunitária. A minga era a reunião da comunidade para realizar um trabalho coletivo com duração média de sete horas, mas era sobretudo uma prática econômica, social e cultural para preservar a unidade, integração e intercâmbio. Na minga a comunidade aportava os ingredientes para o preparo do almoço e lanche. A "troca de mão" (chamada assim no Resguardo) significava o trabalho de um grupo de famílias nas diferentes chácaras, conforme um cronograma dialogado, assim as famílias conseguiam fazer o trabalho de todos mais rápido e fortalecer os vínculos de amizade entre elas. Os alimentos eram preparados pela família da casa ou chácara na qual estavam trabalhando.

A frequência média de consumo de alimentos no Resguardo era de quatro refeições por dia: café da manhã, almoço, lanche e janta. A composição dos ingredientes de cada refeição mudava dependendo da posição social da família. Eram consideradas famílias pobres as que tinham pouca terra ou não tinham. As famílias consideradas ricas tinham terra para produzir os alimentos de consumo e vender um excedente, empregavam os vizinhos ou tinham uma fonte de ingresso que permitia acesso a bens considerados de luxo, como o arroz (Ver tabela 2). 


\begin{tabular}{|c|c|c|c|c|}
\hline & $\begin{array}{c}\text { Café da manhã } \\
\text { 6hs - 7hs }\end{array}$ & $\begin{array}{c}\text { Almoço } \\
11 \mathrm{hs}\end{array}$ & $\begin{array}{c}\text { Lanche } \\
14 \mathrm{hs}\end{array}$ & $\begin{array}{c}\text { Jantar } \\
\text { 17hs-18hs }\end{array}$ \\
\hline Pobres & $\begin{array}{c}\text { Abóbora com leite*+ } \\
\text { aco } \\
\text { Batata cozida + água } \\
\text { com sal } \\
\text { Caldo de majua }\end{array}$ & $\begin{array}{c}\text { Sopa de milho } \\
\text { mote }^{* *}\end{array}$ & $\begin{array}{c}\text { Abóbora com leite } \\
\text { Café + arepa de trigo } \\
\text { ou milho } \\
\text { Canjica }\end{array}$ & Sopa de milho \\
\hline Ricos & $\begin{array}{c}\text { Café }+ \\
\text { arepa de trigo } \\
\text { ou pão de milho + } \\
\text { Queijo }\end{array}$ & $\begin{array}{c}\text { Sopa de milho } \\
\text { ou mote ou } \\
\text { sancocho }+ \\
\text { água de rapadura } \\
+ \\
\text { proteína } \\
\text { animal*** }\end{array}$ & $\begin{array}{c}\text { Abóbora com leite } \\
\text { ou canjica } \\
\text { Café + arepa de trigo } \\
\text { ou milho }\end{array}$ & $\begin{array}{c}\text { Sopa de milho } \\
\text { ovo**** }\end{array}$ \\
\hline
\end{tabular}

Tabela 2 - Resumo das refeições diárias.

Legenda: *Comida conhecida como calabaza ou mexicano. ** Mote é uma sopa de milho na qual o milho é agregado inteiro fazendo um cozimento geralmente no dia anterior à preparação. Aco é a farinha de milho torrada, Sancocho é o conhecido cozido no Brasil e arepa é uma pequena torta assada feita de milho moído pré-cozido. *** A proteína animal era consumida pelo menos uma vez por semana, para o resto do tempo as famílias agregavam o osso que era mantido defumado. **** $\mathrm{O}$ ovo era consumido pelo menos três vezes por semana cozido na sopa. Fonte: Trabalho de Campo, outubro de 2015.

O sistema alimentar não era tradicional na sua totalidade, pois houve influências externas. A construção de estradas e a eletrificação, como partes da política desenvolvimentista do século XX contribuíram para o aumento do ingresso de alimentos, ferramentas e práticas agrícolas externas. A capacitação e assistência técnica do Instituto Nacional de Reforma Agraria introduziu sementes de cenoura, alface e espinafre e deu a conhecer os adubos químicos. Ainda que naquele momento, não prosperou o uso de adubos químicos por representarem preços altos para as famílias.

\section{Sistema alimentar "bonanza de papoula"}

Bonanza é uma tradução literal de prosperidade. Usamos essa expressão porque mais da metade das 38 pessoas entrevistadas utilizaram a palavra bonanza para referenciar uma época de auge econômico pela presença da papoula. O sistema alimentar mudou drasticamente pela substituição de alimentos por cultivos de papoula. As famílias que tinham terra suficiente cultivavam a papoula e contratavam pessoas de 
fora do Resguardo. As pessoas que não tinham terra empregavam-se em atividades relacionadas com papoula que eram muito bem pagas. $\mathrm{O}$ cultivo de papoula por ser rentável mesmo em pequenas quantidades espalhou-se rapidamente.

O cultivo de papoula era intensivo, ou seja, em tudo canto e a todo momento. A horta tradicional ou chagra foi esquecida. Isso impactou na diversidade de plantas e espécies cultivadas e também nas de controle biológico. Quando não havia mais espaço para cultivar, iniciou-se a prática de corte e queima em zonas de montanha que antes não tinham sido cultivadas porque ficavam perto das fontes de água. Como a produção de alimentos era inexistente, as pessoas compravam todos os alimentos, incentivando-se o comércio de alimentos e mercadorias e o aumento dos preços, mudando de um sistema de distribuição de alimentos baseado na reciprocidade e na troca para um sistema monetário.

$\mathrm{O}$ sistema de trabalho diferenciado por gênero e idade mudou. $\mathrm{O}$ cultivo de papoula precisava de mão de obra, tanto homens quanto mulheres passaram a trabalhar na produção de papoula. As mulheres por influência externa e por terem dinheiro sentiam-se liberadas e muitas vezes separavam. As crianças preferiam largar a escola e trabalhar porque gerava dinheiro. Os avós tomavam conta das crianças e das tarefas mínimas como cozinhar. Os homens com dinheiro no bolso bebiam demais e compravam armas e bens de luxo, como moto e eletrodomésticos. Esse quadro levou à desintegração familiar que posteriormente repercutiu na degradação social.

Do ponto de vista social havia um desrespeito às autoridades tradicionais. As pessoas não faziam os trabalhos comunitários como mingas. Os lugares conhecidos como discotecas eram abertos de sábado a segunda, neles o consumo de licor, a dança e a briga eram a constante, assim como as mortes violentas.

O consumo de alimentos mudou impactando no aspecto social. As pessoas deviam consumir uma "boa alimentação". O alimento tradicional ou de autoconsumo descritos no item anterior era considerado comida de pobres. $\mathrm{O}$ arroz, macarrão, grãos e proteínas deviam estar presentes no dia-a-dia. Houve um aumento de número de refeições, passando de quatro para cinco por dia. O cardápio ficou carregado de carboidratos, grãos, proteína animal consumida diariamente, frituras, alimentos com conservantes, temperos artificiais, consumo de refrigerantes (Ver tabela 3). 


\begin{tabular}{|c|c|c|c|c|}
\hline $\begin{array}{l}\text { Cafezinho } \\
6 \mathrm{hs}-7 \mathrm{hs}\end{array}$ & $\begin{array}{l}\text { Café da manhã } \\
8 \mathrm{hs}-9 \mathrm{hs}\end{array}$ & $\begin{array}{l}\text { Almoço } \\
11 \mathrm{hs}-12 \mathrm{hs}\end{array}$ & $\begin{array}{l}\text { Lanche } \\
14 \mathrm{hs}-15 \mathrm{hs}\end{array}$ & $\begin{array}{c}\text { Jantar } \\
18 \mathrm{hs}\end{array}$ \\
\hline Café + & Arroz + & Sancocho & Café + & Arroz + \\
\hline Arepa frita & $\begin{array}{c}\text { Feijão / lentilha / } \\
\text { batata frita }+\end{array}$ & $\begin{array}{c}\text { ou } \\
\text { sopa de } \\
\text { macarrão + }\end{array}$ & Arepa frita & $\begin{array}{c}\text { Macarrão / } \\
\text { batata frita + }\end{array}$ \\
\hline Ou pão de milho + & $\begin{array}{l}\text { Ovo / frango / } \\
\text { linguiça }+\end{array}$ & Arroz + & Ou pão & $\begin{array}{c}\text { Linguiça / ovo / } \\
\text { atum + }\end{array}$ \\
\hline \multirow[t]{2}{*}{ Queijo } & Café & Frango/carne + & & \\
\hline & & $\begin{array}{c}\text { Água } \\
\text { rapadura / suco / } \\
\text { refrigerante }\end{array}$ & & $\begin{array}{c}\text { Água } \\
\text { rapadura/ suco / } \\
\text { refrigerante }\end{array}$ \\
\hline
\end{tabular}

Tabela 3 - Cardápio do Sistema Alimentar bonanza papoula. Fonte: Trabalho de Campo, outubro de 2015.

As mudanças descritas não são um caso isolado do Resguardo indígena Guachicono. A presença de cultivos ilícitos é um fenômeno nacional que tem relação com o Estado colombiano e o conflito armado de grupos ilegais.

O conflito armado entre grupos ilegais e o Estado colombiano tem as suas origens na luta bipartidária pós-independência e no problema agrário legado da colônia. Os grupos armados ilegais surgiram em oposição ao Estado, por volta dos anos 1950. O narcotráfico acirrou o conflito quando proliferou, a partir da década de 1970, nas áreas socioeconômicas mais vulneráveis mas também ambientalmente ricas.Nessas áreas os problemas de escassez de terra eram mais graves e a presença do Estado era fraca, atraindo a implantação do conflito.Assim, os cultivos de coca e papoula cresceram nas zonas de Magdalena meio, no maciço Colombiano e no sudoeste da Colômbia (Osorio, 2003; Vasquez, 2007).

As áreas onde convergem cultivos ilícitos, atores armados e efeitos do tráfico de drogas são territórios que correspondem a $85 \%$ da área nacional de áreas de conservação e parques naturais. Além de serem espaços habitados por indígenas, deslocados pela violência e, em geral, população considerada como vulnerável (Osorio, 2003; Camargo, 2010). 
É assim como o cultivo de papoula se implanta no Resguardo indígena de Guachicono (localizado no maciço Colombiano) a partir de 1992. Os indígenas participavam do plantio, manutenção e colheita da papoula. As atividades de processamento para que o látex virasse pó era realizado por pessoas de fora do Resguardo.

\section{Sistema alimentar voltando às origens}

O terceiro sistema alimentar surgiu por volta de 2000, num panorama de continuidade do conflito armado na Colômbia. "Voltando às origens" é um sistema de alimentação que o Resguardo ainda está construindo, focado no resgate das tradições. É caracterizado pela redução da população por conta do deslocamento para as cidades. Os cultivos de papoula começam a desaparecer depois do ano 2000 por causa das fumigações aéreas realizadas pelo governo colombiano em parceria com os Estados Unidos com o propósito de erradicar os cultivos ilícitos.

A situação socioeconómica nos inícios da década de 2000 é crítica pela inexistência de ingressos para satisfazer as necessidades básicas de alimentação. O governo colombiano desenvolve projetos chamados de alternativos para evitar a reincidência na prática de cultivos de uso ilícito. Os projetos geralmente compreendem entrega de sementes, adubos, assistência técnica e capacitação. É destaque o programa famílias guardabosques.

As figuras do sistema alimentar de "autoconsumo" são retomadas como uma forma de procurar a autonomia alimentar. A chagra, a "troca de mão" e a minga reaparecem (Ver figura 5 e 6 ). 


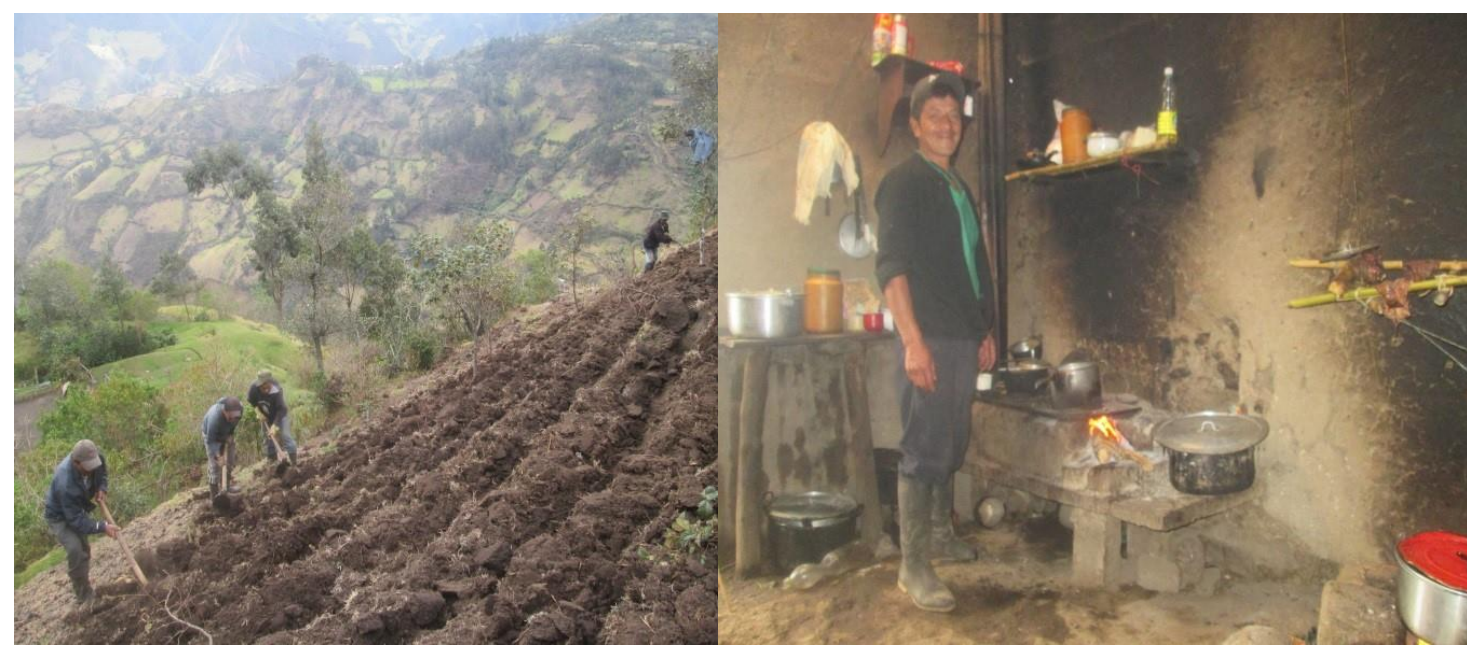

Figura 5 (à direita): Pessoa encarregada de fornecer as refeições aos trabalhadores durante a "troca de mão". Figura 6 (à esquerda): Preparo da terra na modalidade "troca de mão" na vereda Alto de la Playa. Fonte: Trabalho de Campo, outubro de 2015.

A cada segunda-feira na parte urbana do Resguardo Guachicono há uma feira semanal conhecida como plaza de mercado. As chivas ${ }^{14}$ chegam com produtos do clima quente como banana da terra, rapadura e frutas e as famílias vendem os excedentes da produção de alimentos. Encontra-se, também, um local para a venda de proteína animal. Na plaza de mercado se combinam mercadorias como roupas, alimentos e restaurantes chamados toldas. A feira semanal é um espaço para compartilhar, há torneios de futebol e basquete. É nessa feira que acontecem as reuniões do Cabildo.

São institucionalizadas duas figuras: o trueque e os mercados móveis. O trueque pode ser entendido como a troca de alimentos de diferentes áreas climáticas sem a mediação da moeda física ou o pagamento de um serviço em espécie. A troca tem regras que permitem o intercâmbio justo de diferentes produtos. As regras incluem um espaço físico definido pelos participantes para a realização da troca, uma data estabelecida, a eleição de pessoas encarregadas de mediar em caso de diferenças ou inconformidades (Cabildo Mayor Yanacona, 2001).

Os mercados móveis são uma atividade na qual os alimentos produzidos no resguardo indígena Guachicono são transportados às cidades mais próximas para serem vendidos. Os mercados são organizados pelos indígenas que moram no Resguardo como também pelos que estão na cidade. Neste sentido, esta prática contribui na recuperação dos costumes alimentares dos indígenas que moram nas cidades. Os

\footnotetext{
${ }^{14}$ Chiva é um ônibus adaptado para transporte na área rural.
} 
indígenas que vendem os alimentos obtêm uma renda que lhes permite comprar produtos que na área rural não podem ser adquiridos como fósforos, sal e produtos de limpeza (Cabildo Mayor Yanacona, 2001).

$\mathrm{Na}$ análise de dados não foi encontrada uniformidade no cardápio. Foram identificadas três formas de compor o cardápio segundo o lugar de moradia das famílias. Há um cardápio que chamaremos de geral no setor rural, é das famílias mais pobres ou das que procuram manter a tradição. O cardápio da vereda Monteredondo contrasta porque está composto por cinco refeições diárias e com uma composição maior de carboidratos (Ver tabela 4). O cardápio da zona urbana é tanto das famílias que habitam na zona urbana do Resguardo Guachicono como também das famílias entrevistadas que moram na cidade de Popayán, havendo maior variedade de alimentos, porém com jantares.

\begin{tabular}{|c|c|c|c|c|c|}
\hline \multirow[b]{2}{*}{ Geral } & $\begin{array}{c}\text { Café da manhã } \\
6 \mathrm{hs}-7 \mathrm{hs}\end{array}$ & & $\begin{array}{l}\text { Almoço } \\
11 \mathrm{hs}\end{array}$ & $\begin{array}{l}\text { Lanche } \\
14 \mathrm{hs}\end{array}$ & $\begin{array}{c}\text { Jantar } \\
\text { 18hs-19hs }\end{array}$ \\
\hline & $\begin{array}{l}\text { Café + queijo* } \\
\text { arepa frita/pão } \\
\text { de milho }\end{array}$ & & $\begin{array}{l}\text { Sopa de } \\
\text { milho/mote } \\
\text { Água de } \\
\text { rapadura }\end{array}$ & $\begin{array}{c}\text { Café }+ \\
\text { arepa frita }\end{array}$ & $\begin{array}{c}\text { Sopa } \\
\text { ou arroz }+ \\
\text { batata frita }+ \\
\text { ovo*** }\end{array}$ \\
\hline \multirow[b]{2}{*}{ Monteredondo } & $\begin{array}{c}\text { Tinto } \\
6 \mathrm{hs}-7 \mathrm{hs}\end{array}$ & $\begin{array}{c}\text { Café da manhã } \\
9 \mathrm{hs}\end{array}$ & $\begin{array}{c}\text { Almoço } \\
11 \mathrm{hs}\end{array}$ & $\begin{array}{l}\text { Lanche } \\
14 \mathrm{hs}\end{array}$ & $\begin{array}{c}\text { Janta } \\
18 \mathrm{hs}-19 \mathrm{hs}\end{array}$ \\
\hline & $\begin{array}{l}\text { Café + queijo* } \\
\text { Arepa frita/pão } \\
\text { de milho }\end{array}$ & $\begin{array}{c}\text { Arroz + } \\
\text { Batata frita/ } \\
\text { feijão/lentilha } \\
\text { Ovo }\end{array}$ & $\begin{array}{c}\text { Sopa de } \\
\text { milho/mote } \\
\text { Água de } \\
\text { rapadura }\end{array}$ & $\begin{array}{c}\text { Café + } \\
\text { arepa frita }\end{array}$ & \begin{tabular}{|c|} 
Sopa de \\
milho ou de \\
macarrão \\
Arroz + \\
batata frita \\
Proteína \\
animal ou \\
ovo** \\
\end{tabular} \\
\hline \multirow[b]{2}{*}{ Urbana* } & $\begin{array}{c}\text { Café da manhã } \\
6 \mathrm{hs}-7 \mathrm{hs}\end{array}$ & & $\begin{array}{l}\text { Almoço } \\
11 \mathrm{hs}\end{array}$ & $\begin{array}{l}\text { Lanche } \\
2 \mathrm{hs}\end{array}$ & $\begin{array}{c}\text { Jantar } \\
18 \mathrm{hs}-19 \mathrm{hs}\end{array}$ \\
\hline & Arepa frita & & $\begin{array}{c}\text { Sopa + arroz } \\
+ \text { grão** } \\
\text { proteína }+ \\
\text { salada + suco }\end{array}$ & Arepa frita & Ocasional \\
\hline
\end{tabular}

Tabela 4 - Resumo das refeições diárias.

Fonte: Trabalho de Campo, outubro de 2015. 
A pesquisa permitiu determinar qualitativamente que o Resguardo encontra-se em estado de insegurança alimentar. A baixa qualidade da alimentação é o determinante do estado de insegurança. O cardápio está sobrecarregado de grãos e gorduras, mas carece de verduras e frutas. A composição da alimentação atualmente consumida gera fatores de risco para a saúde como gravidez de alto risco, baixo peso ao nascer, desnutrição infantil, sobrepeso e hipertensão em adultos como relatado pelos agentes de saúde $^{15}$. Nesse sentido, as famílias não têm práticas de alimentação saudáveis que promovam a saúde.

No entanto, a pesquisa identificou que o processo político organizativo dos Yanaconas dialogado com o governo colombiano, tem importantes avanços em termos de autonomia alimentar ${ }^{16}$. A autonomia alimentar consta como um dos objetivos no plano de vida do povo Yanacona ligado ao programa de educação próprio. A autonomia alimentar está em andamento com estratégias que estão sendo executadas pelos Cabildos, em especial, no caso do Cabildo Guachicono. Uma estratégia é a recuperação e fortalecimento das práticas tradicionais como chagras e mingas, e ao mesmo tempo a institucionalização dos trueques e mercados móveis. Nas escolas de ensino do Resguardo as crianças constroem chagras, fazem mingas, trueques com Resguardos vizinhos e participam dos mercados móveis. Todas essas atividades estão contempladas no projeto educativo institucional elaborado pelo Resguardo.

O povo Yanacona entende que é importante diversificar as fontes de ingresso, por tanto, 500 famílias são beneficiárias do programa de transferência de renda condicionada do governo colombiano chamado famílias em acción. O programa entrega uma mensalidade em dinheiro a cada família por cada criança em idade escolar. $\mathrm{O}$ Cabildo do Guachicono condiciona o recebimento do benefício à existência de uma chagra por família beneficiária, para o qual disponibiliza um funcionário que faz o acompanhamento.

\footnotetext{
${ }^{15}$ No Posto de Saúde de Guachicono não foram encontrados dados oficiais que mostrem a relação entre alimentação e doença.

${ }^{16}$ Para efeitos da pesquisa entende-se por autonomia alimentar [...] o direito dos povos a definir suas próprias políticas e estratégias sustentáveis de produção, distribuição e consumo de alimentos, que garantam o direito à alimentação a toda a população, com base na pequena e média produção, respeitando suas próprias culturas e a diversidade dos modos camponeses de produção, de comercialização e de gestão, nos quais a mulher desempenha um papel fundamental (Via Campesina, 2007:10).
} 
Outra estratégia do Cabildo, na procurada autonomia alimentar, consiste na elaboração do cardápio dos restaurantes escolares ${ }^{17}$ do Resguardo conforme seus usos e costumes, o que não acontece com escolas localizadas em terras não indígenas. Foi uma medida negociada com o governo nacional e vigente desde o ano 2012. Os restaurantes escolares no Guachicono atendem uma média de 589 estudantes, oferecendo almoço e lanche. O governo transfere os recursos ao Cabildo para o funcionamento do restaurante escolar e cada mês o Cabildo presta contas. O dinheiro entregue é pouco (equivalente a US\$ 0,29 por criança por dia) permitindo apenas oferecer almoço e lanche, o Cabildo faz um aporte adicional, as escolas usam a produção das chagras e, os pais aportam US\$ 0,95 mensais por criança.

O Resguardo tem um posto de saúde e um programa de saúde próprio de prevenção que atende principalmente idosos, crianças e grávidas. Enfermeiros chamados de dinamizadores visitam periodicamente as famílias. Para o povo Yanacona a autonomia alimentar deve dialogar com a saúde, a educação, a cultura e com o governo.

Após a análise do sistema alimentar "voltando às origens" é importante compreender os fatores que determinaram a mudança para esse sistema. Foram identificados como determinantes: a continuidade do conflito armado entre forças ilegais e o Estado, a diminuição e posterior desaparecimento dos cultivos ilícitos de papoula, as políticas públicas e o processo político organizativo dos Yanaconas.

Os grupos armados ilegais ficaram nas zonas de cultivo da coca e da papoula. Os diferentes grupos ilegais entraram, entre eles, em uma disputa pelo controle territorial buscando maiores ganhos com o negócio ilegal de drogas. Os enfrentamentos violentos levaram ao deslocamento forçado de grande parte da população civil para os centros urbanos e para outros países nas áreas de fronteira. $\mathrm{O}$ conflito armado ultrapassou as fronteiras nacionais quando a Colômbia passou a ser o primeiro produtor de coca do mundo e os Estados Unidos o principal comprador (Osorio, 2003).

Para enfrentar essa situação, no ano 1998, iniciou-se a estratégia de cooperação bilateral entre os Estados Unidos e a Colômbia para combater o narcotráfico conhecida como Plano Colômbia. O Plano Colômbia partia dos princípios de igualdade e reciprocidade entre os países produtores e os consumidores de narcóticos. As medidas de combate aos cultivos ilícitos eram, por uma parte programas de desenvolvimento

\footnotetext{
${ }^{17}$ É um programa da política de segurança alimentar do governo colombiano para atender crianças em situação de vulnerabilidade.
} 
alternativo e, por outra fumigação aérea e presença militar para erradicação manual e controle territorial. Os programas de desenvolvimento alternativo procuravam que a população camponesa e indígena envolvida substituísse voluntariamente os cultivos ilícitos (Osorio, 2003; Camargo, 2010).

A fumigação aérea com glifosato gerou impactos. Os cultivos ilícitos foram erradicados, mas também os cultivos de alimentos que seriam plantados em substituição. As fontes de água foram contaminadas e houve perda de biodiversidade. $\mathrm{O}$ solo sofreu um desgaste maior do que antes por conta da produção intensiva de cultivos ilícitos. As populações de microrganismos e insetos foram alteradas. Apareceram doenças dérmicas, e infeções respiratórias aumentaram pela inalação do ar contaminado. As infeções gástricas aumentaram como consequência do consumo de alimentos contaminados e da escassez de água potável (Osorio, 2003; López-Garcés, 2004; Vasquez, 2007). Este retrato desenha um sistema alimentar de prosperidade ou "bonanza" que se desfez porque a população já não tinha a disponibilidade de ingressos para manter esse estilo de vida.

Os programas de desenvolvimento alternativo, entre os quais se destaca o de "famílias guardabosques" foi uma iniciativa importante do Plano Colômbia, mas ele se revelou insustentável. Um subsídio monetário era entregue pelo governo às famílias beneficiárias bimensalmente. A poupança do dinheiro recebido ou os projetos produtivos não estavam contemplados no início do programa. Os beneficiários resolveram as suas necessidades básicas imediatas, mas quando cessava o incentivo, nem todos tinham uma fonte alternativa de renda. $\mathrm{O}$ risco de voltarem à pratica ilícita era alto. O subsídio gerou dependência de um ingresso periódico e a migração para os centros urbanos continuou a crescer (Giraldo \& Lozada, 2008).

\section{Considerações finais}

O Resguardo indígena do Guachicono encontra-se em estado de insegurança alimentar. A situação está determinada pela baixa qualidade da alimentação, representada no alto consumo de gorduras e grãos e escassez de verduras e frutas. A pesquisa permitiu identificar que foram as drásticas mudanças dos sistemas alimentares que incidiram no estado atual de insegurança alimentar. A insegurança alimentar não indica que as pessoas estejam passando fome, mas sim que a alimentação ingerida não é 
saudável. No entanto, o povo Yanacona registra no seu plano de vida a necessidade da busca da autonomia alimentar. Nesse sentido, o estudo sugere a necessidade de pesquisas futuras no aprofundamento dos valores nutricionais da dieta da população.

A segurança alimentar tem sido abordada conceitualmente a partir de uma política para erradicar a fome e a pobreza. Os resultados da pesquisa indicam que há falta de uma análise conceitual mais abrangente que perpasse as cifras de fome e pobreza. O conceito de autonomia ou soberania alimentar aparece na contra mão da segurança, mas até o momento não há consenso acadêmico sobre o sentido real de ambos conceitos.

Os sistemas alimentares são entendidos como uma construção social na qual os alimentos viram comida. O estudo permite identificar que o sistema alimentar de autoconsumo foi impactado por fatores externos à comunidade ou grupo social. Os fatores externos têm como causa comum a ausência do Estado ou a existência de políticas públicas que não visam à sustentabilidade. Por outra parte, os resultados indicam que a mudança para um sistema de autonomia alimentar é facilitada quando a comunidade é consultada e o diálogo estabelecido com as instituições do Estado. A adaptação das políticas públicas às particularidades da população é mais uma tarefa dos governos locais na busca da satisfação das suas necessidades. 


\section{Referências}

ALBUQUERQUE, M. A segurança alimentar e nutricional e o uso da abordagem de direitos humanos no desenho das políticas públicas para combater a fome e a pobreza. Revista de Nutrição, SP: Campinas, v. 22, n. 6, p. 895-903, dezembro, 2009.

ALENCAR, Á. G. Do conceito estratégico de segurança alimentar ao plano de ação da FAO para combater a fome. Revista Brasileira de Política Internacional, Brasília: v. 44, n. 1, p. 137144, janeiro/junho de 2001.

ÀLVAREZ, M.C.; ESTRADA, A. Inseguridad alimentaria de los hogares colombianos según localización geográfica y algunas condiciones sociodemográficas. Revista Perspectivas en Nutrición Humana Vol. 10 No. 1. Universidad de Antioquia. Medellín. Colombia, p. 23-36. 2008.

ALVAREZ, M.; ESTRADA, A., MONTOYA, E., MELGAR-QUININEZ, H. Validación de Escala de la Seguridad Alimentaria Doméstica en Antioquia, Colombia. Revista Salud Pública de México. p. 474-481, Cuernavaca, 2006.
ASOCIACIÓN
INDIGENA
DEL
CAUCA. Reseña histórica.

In: http://190.254.19.13:1080/saludAic/. Acesso fevereiro 2016.

BERNAL, H.; PAREDES M. Impacto ambiental ocasionado por las sustancias químicas, los cultivos ilícitos y las actividades conexas. Dirección Nacional de Estupefacientes - Subdirección $\begin{array}{lllll}\text { Estratégica } & \mathrm{y} & \mathrm{de} & \text { Investigaciones. } & \text { Bogotá. In: }\end{array}$ http://cdam.minam.gob.pe/publielectro/impacto\%20ambiental/Impactosustanciasquimicas.pdf . Acesso em fevereiro 2016.

BRASIL (a). Lei $n^{\circ} 11.346$, de 15 de julho de 2006. Cria o Sistema Nacional de Segurança Alimentar e Nutricional - SISAN. Diário Oficial da República Federativa do Brasil. Brasília, DF. In: https://www.planalto.gov.br/ccivil_03/_Ato2004-2006/2006/Lei/L11346.htm. Acesso em fevereiro 2016.

CABILDO MAYOR YANACONA. Plan de Vida del Pueblo Yanacona. 2001. In: http://nacionyanakuna.com/Paginas/Docs_NacionYanakuna/Docs_Documentos/PLAN_DE_ VIDA_YANAKUNA.pdf. Acesso em: Fevereiro 2016.

CABILDO MAYOR YANACONA. Declaratoria colectiva del Pueblo Yanacona como victima del conflito armado. 2015. (Documento impresso apenas disponível para consulta na comunidade)

CABILDO MAYOR YANACONA. Quienes In: https://www.cabildoyanaconasantiagodecali. Acesso em fevereiro 2016.

CABILDO MAYOR YANACONA. La cosmovisión Yanakuna: siguiendo el camino andino. In: http://nacionyanakuna.com/Paginas/Cosmovision/Cosmovision\%20Yanakuna.htm Acesso em fevereiro 2016.

CAMARGO, S. Consecuencias del Plan Colombia, el caso del agua en la comunidad Yanacona. Ediciones Abya-yala, Quito, Ecuador, p.135, 2010.

CANCILLERIA DE LA REPÚBLICA DE COLOMBIA. Decreto No. 2001 de 1988. In: https://www.cancilleria.gov.co/sites/default/files/Normograma/docs/decreto_2001_1988.htm.

Acesso fevereiro 2016.

CONSEJO REGIONAL INDIGENA DEL CAUCA. In: http://www.criccolombia.org/portal/guardia-indigena/. Acesso em fevereiro 2016.

DEPARTAMENTO ADMINISTRATIVO NACIONAL DE ESTADÍSTICA (DANE). Colombia una nación multicultural. 2007. In: https://www.dane.gov.co/files/censo2005/etnia/sys/colombia_nacion.pdf. Acesso junho 2015.

DICCIONARIO DE LA LENGUA ESPAÑOLA. 23 Edición. 2014. In: http://dle.rae.es/?id=bdIovVq. Acesso em janeiro 2017.

FERNANDES, C. Sabores e saberes da cultura Kalunga: origens e consequências das mudanças nos sistemas alimentares. Dissertação de Mestrado. Centro de Desenvolvimento Sustentável da Universidade de Brasília, p.139, 2014. 
GARCIA, M. El estado de la inseguridad alimentaria en el mundo (SOFI) 2006: la erradicación del hambre en el mundo. Evaluación de la situación diez años después de la cumbre mundial sobre la alimentación (CMA). Revista del Centro de Investigaciones Agroalimentarias. Mérida, Venezuela, v. 13, n. 26, p. 139-141, jun. 2008.

GIRALDO, O F; LOZADA, R A. programa de desarrollo alternativo en Colombia familias guardabosques: Visión desde el enfoque del desarrollo territorial rural. Revista Luna Azul de la Universidad de Caldas Colombia. p. 60-74, 2008.

GUGELMIN, S.A.; SANTOS, R.V. Ecologia humana e antropometria nutricional de adultos Xavánté, Mato Grosso, Brasil. Cadernos de Saúde Pública. Vol 17 No. 2. Rio de Janeiro. p 313322. Março/Abril 2001.

HEUSI, N. Imagens de abundancia e escassez: comida Guarani e transformações na contemporaneidade. Tese de doutorado. Programa de Pós-Graduação em Antropologia Social da Universidade Federal de Santa Catarina. Florianópolis, SC. 266 p, 2011.

INSTITUCIÓN EDUCATIVA AGROPECUARIA YANACONAS. Ubicación geográfica. In: http://ieayanaconas.blogspot.com.br/p/ubicacion-geografica.html. Acesso em junho 2015.

KATZ, E. Alimentação indígena na América latina: comida invisível, comida de pobres ou patrimônio culinário? Espaço Ameríndio, v. 3, n. 1, p. 25-41. RS: Porto Alegre. 2009.

KEPPLE, A.W.; SEGALL-CORRÊA, A.M. Conceituando e medindo segurança alimentar e nutricional. Revista Ciência \& Saúde Coletiva vol.16 no.1. p. 187-199. Rio de Janeiro. Janeiro 2011.

LEMOS, C.L. Propuesta metodológica para determinar el estado, de la soberanía, seguridad alimentaria y nutricional y su aplicación en el Municipio de Puracé, Cauca. Trabajo de grado para optar al título de magister en Desarrollo Rural. Pontificia Universidad Javeriana. Santa Fé de Bogotá: Colombia. 2011.

LÓPEZ-GARCÉS, C L. Reconstruyendo la casa Yanacona. Etnicidad y transformación del espacio social en el Macizo Colombiano. Revista de Antropología y sociología. V edición, fascículo 1. p. 42-53. Manizales: Colombia, 1999.

LÓPEZ-GARCÉS, C L. A questão indígena na Colômbia: movimentos indígenas, políticas indigenistas e conflito armado. In: I reunião de estudos: a ascensão de movimentos indigenistas na América do sul e possíveis reflexos para o Brasil. CT comunicação editora. Brasil, p; 5-37, Brasília - Brasil, 2004. In: http://www.blogdoalon.com/ftp/questaoindigena.pdf. Acesso em fevereiro 2016.

MACIEL, M E. Cultura e alimentação ou o que têm a ver os macaquinhos de Koshima com Brillat-Savarin? Horizontes Antropológicos, 7(16), 145-156. RS: Porto Alegre, 2001.

MONTEIRO, C. A. Segurança alimentar e nutrição no Brasil. In Saúde no Brasil: contribuições para a agenda de prioridades de pesquisa, Brasília: Ministério da Saúde, p. 255273, 2004.

NASCIMENTO, A; ANDRADE, S. Segurança alimentar e nutricional: pressupostos para uma nova cidadania? Ciência e Cultura, São Paulo, v. 62, n. 4, out. p. 34-38, 2010.

ORGANIZAÇÃO DAS NAÇÕES UNIDAS PARA A ALIMENTAÇÃO E A AGRICULTURA - FAO. Escala Latinoamaericana y Caribena de Seguridad Alimentaria (ELCSA) manual de uso y aplicación. Santiago de Chile, p.86, 2012.

ORGANIZAÇÃO DAS NAÇÕES UNIDAS PARA A ALIMENTAÇÃO E A AGRICULTURA - FAO. Panorama de la seguridad alimentaria y Nutricional en América Latina y el Caribe 2013 Hambre en América Latina y el Caribe: acercándose a los objetivos del Milenio., Santiago de Chile, 56 p. 2014. In: http://www.fao.org/docrep/019/i3520s/i3520s.pdf. Acesso em junho 2015.

OSEGUERRA, D; ESPARZA, L. Significados de la seguridad y el riesgo alimentarios entre indígenas purhépechas de México. Revista Desacatos no. 31. p 115-136, México. 2009.

OSORIO G, A R. Aproximaciones a los efectos ambientales, sociales y económicos de la erradicación de cultivos ilícitos por aspersión aérea en Colombia. Agroalimentaria, v. 8, n. 17, p. 61-72. Mérida,Venezuela. jul. 2003. 
PAT, L. Seguridad alimentaria en cuatro comunidades mayas con diferente actividad económica del norte de Campeche, México. Tesis de doctorado en Ecología y Desarrollo Sustentable, El Colegio de la Frontera Sur. San Cristobal de las Casas: México, 187 p. 2010.

PÉREZ-ESCAMILLA, R. Can experience-based household food security scales help improve food security governance. Global Food Security. 1. p.120-125. 2012. In: https://www.ncbi.nlm.nih.gov/pmc/articles/PMC3685197/. Acesso em maio 2015.

PÉREZ-ESCAMILLA, R. Seguridad Alimentaria y Nutricional: Marco Conceptual. In: XII Congresso Brasileiro de Sociologia, 2005, Belo Horizonte. Sociologia e realidade: pesquisa social no século XXI. 2005. In: http://www.sbsociologia.com.br/portal/index.php?option=com_docman\&task=cat_view\&gid=5 4\&Itemid=171. Acesso em maio 2015.

PERIÓDICO EL ESPECTADOR. Vuelve y juega la protesta agraria. In: http://www.elespectador.com/noticias/politica/vuelve-y-juega-protesta-agraria-articulo-634939. Acesso em junho 2016.

PROCURADURIA GENERAL DE LA NACIÓN. Constitución política de Colombia 1991. In: http://www.procuraduria.gov.co/guiamp/media/file/Macroproceso\%20Disciplinario/Constitucio n_Politica_de_Colombia.htm. Acesso junho 2015.

ROSIQUE, J.et. Al. Estado nutricional y hábitos alimentarios en indígenas Embera de Colombia. Revista Chilena de Nutrición. Vol. 37, No. 3 p. 270-280. Santiago de Chile, 2010.

VÁZQUEZ, M. La Iglesia y la violencia bipartidista en Colombia (1946-1953). Análisis historiográfico Anuario de Historia de la Iglesia, vol. 16, pp. 309-334 Universidad de Navarra Pamplona, España. 2007.

VIA CAMPESINA. Soberania Alimentar, os Agrocombustíveis e a Soberania Energética. Publicado por Via Campesina Brasil: Brasília, 2007. In: http://www.alainet.org/pt/active/17561 Acesso junho 2016.

Recebido em: 31/01/2017. Aprovado em: 30/03/2017. 